\title{
IPTEKS TARGET DAN REALISASI PAJAK DAERAH DI DINAS PENDAPATAN DAERAH PROVINSI SULAWESI UTARA
}

\author{
Eka A. Takahindangen ${ }^{1}$, Sifrid S. Pangemanan ${ }^{2}$ \\ ${ }^{1,2}$ Jurusan Akuntansi, Fakultas Ekonomi dan Bisnis, Universitas Sam Ratulangi, Kampus Unsrat, Sulawesi Utara, \\ 95115, Indonesia \\ E-mail : eka23takahindangen@gmail.com
}

\begin{abstract}
This study aims to determine the achievement of regional tax revenues and the percentage of realization of local tax revenues in the Regional Revenue Service of North Sulawesi Province in 2017-2018, which consists of Motor Vehicle Taxes, Motor Vehicle Name Transfer Fees, Surface Water Taxes, Vehicle Fuel Taxes Motorized, Cigarette Tax, Public Service Retribution, Service Service Retribution, and Specific License Licensing The results of this study indicate that the target of regional tax revenue in the North Sulawesi Provincial Revenue Service decreased in 2018 and the realization percentage of each type of regional tax revenue increased in January 2017 and November 2017. From that total it can be concluded that the increase in realization of local tax revenues in the Regional Revenue Service is able to pursue the tax deposit target in 2017.
\end{abstract}

Keywords: Local Taxes, Target and Realization

\section{PENDAHULUAN}

Dalam suatu pemerintahan daerah ada peraturan-peratutran yang harus kita patuhi salah satunya adalah peraturan untuk membayar pajak daerah, kita sebagai masyarakat yang mempunyai kewajiban membayar pajak untuk pemerintahan daerah disebut Wajib Pajak. Pemerintahan Daerah menyebutkan pajak daerah adalah suatu pendapatan daerah yang dibayar oleh orang pribadi atau badan yang merupakan kewajiban mereka untuk membayar pajak kepada pemerintah, sumber pendapatan daerah ini untuk keperluan daerah itu sendiri seperti pembiayaan untuk daerah, pengeluaran dana untuk pengairan dan pertanian, dan juga pengeluaran yang membawa keuntungan ekonomis bagi masyarakat dalam daerah itu sendiri. Manfaat dan penggunaan pajak yang dibayar kepada pemerintah akan dapat dirasakan langsung manfaatnya oleh pemerintah dan masyarakat karena pajak bukan untuk digunakan bagi kepentingan pribadi dan bukan juga digunakan untuk kepentingan umum tetapi, pajak digunakan untuk kepentingan pemerintah dan juga masyarakat didaerah itu sendiri oleh karena itu betapa pentingnya membayar pajak tepat waktu karena pajak digunakan untuk kepentingan pemerintah dan masyarakat dan bukan untuk kepentingan umum.

Pendapatan Asli Daerah (PAD) adalah penerimaan yang terdapat dalam daerahnya sendiri yang bersumber dari daerah itu sendiri yang telah dipungut oleh pemerintah daerah yang berdasarkan peraturan daerah sesuai dengan undang-undang yang berlaku. Setiap tahun target pajak harus direalisasikan guna untuk pemerintahan namun masih begitu banyak permasalahan dalam hal ini dikarenakan kesadaran Wajib Pajak untuk membayar pajak masih rendah padahal pajak merupakan salah satu peraturan pemerintah yang sangat penting untuk di patuhi karena kalau tidak di patuhi dapat menimbulkan permasalahan penerimaan pajak yang rendah bagi Pendapatan Asli Daerah (PAD). Oleh karena itu, penulis bertujuan untuk melakukan penelitian di Dinas Pendapatan Daerah Prov.Sulut penelitian tentang penerimaan pajak daerah yang ada di kantor tersebut. 


\section{2.. TINJAUAN PUSTAKA}

Definisi Pajak. Menurut Mardiasmo (2011) Pajak merupakan iuran yang harus dibayar rakyat kepada negara dan tidak mengharapkan balasan sesuatu dari apa yang telah kita bayar dari negara secara langsung karena pajak merupakan kewajiban rakyat yang harus dipatuhi sesuai dengan peraturan pemerintah yang ditetapkan dan bila Wajib Pajak terlambat membayar pajak sesuai dengan jatuh tempo yang ditetapkan maka Wajib Pajak akan mendapat denda karena tidak membayar pajak tepat waktu dan pajak digunakan untuk pemerintah didaerah itu sendiri bukan untuk kepentingan umum tetapi pengeluaran untuk daerah.

Definisi Pajak Daerah. Menurut Mardiasmo (2011) Pajak daerah adalah pajak yang berdasarkan dengan peraturan daerah yang dipungut oleh daerah dan dibayar oleh setiap Wajib Pajak dipergunakan untuk kepentingan daerah yang dapat dirasakan langsung oleh masyarakat didaerahnya sendiri.

Definisi Pendapatan Asli Daerah. Menurut Ginting, Ari mulianta (2012) Pendapatan Asli Daerah (PAD) adalah pendapatan yang diterima oleh sumber-sumber pendapatan yang berasal dari daerah itu sendiri yang terdiri atas pajak daerah, retribusi daerah, laba dari badan usaha milik daerah (BUMD), dan lain-lain pendapatan asli daerah yang sah. Pendapatan Asli Daerah dipungut sendiri oleh pemerintah daerah yang sesuai dengan undang-undang yang berlaku.

Jenis Pajak Daerah. Menurut Damas Dwi Anggoro2017) Pajak daerah dibagi menjadi dua jenis pajak yaitu : Pajak Provinsi, dan Pajak Kabupaten.

\section{Pajak Provinsi terdiri atas :}

1. Pajak Kendaraan Bermotor (PKB). Pajak Kendaraan Bermotor adalah pajak yang termasuk dalam kendaraan beroda dua atau lebih seperti : mobil, motor, alat-alat bergerak dll yang dikenakan pada perorangan atau badan yang memiliki kendaraan bermotor yang digunakan dijalan darat maupun dioperasikan di air karena hal tersebut termasuk dalam pajak kendaraan bermotor yang harus dibayar oleh Wajib Pajak yang menggunakan kendaraan bermotor, pajak kendaraan bermotor ditentukan sesuai dengan kendaraan yang kita operasikan di jalan darat maupun di air kita tetap harus membayar pajak kendaraan. Karena apabila kita menggunakan kendaraan bermotor seperti : mobil, motor, alat-alat bergerak dll kita harus membayar pajak karena itu sudah termasuk dalam peraturan pemerintah yang termasuk dalam pajak kendaraan bermotor jadi kita sebagai masyarakat harus menaatinya dengan membayar pajak waktu agar tidak terkena denda.

2. Bea Balik Nama Kendaraan Bermotor (BBNKB). Bea Balik Nama Kendaraan Bermotor adalah jika kita mempunyai kendaraan bermotor yang dioperasikan dijalan darat maupun di air dan kita telah menjualnya, menukar dengan orang lain, atau bisa juga kita mendapatkannya dari warisan tentu saja kita telah membuat perjanjian kepada dua pihak atau sepihak untuk membayar pajak kendaraan bermotor tersebut karena itu telah menjadi milik sendiri bagaimanapun keadaan yang kita dapatkan tetap kita membayar pajak kendaraan bermotor tersebut karena jika kita telah menjual, menukar dengan orang lain, atau bisa juga kita mendapatkannya dari warisan dan mempunyai kendaraan bermotor kita harus melakukan bea balik nama kendaraan bermotor agar kita menggunakan kendaraan bermotor tersebut sesuai dengan peraturan pemerintah yang termasuk dalam pajak bea balik nama kendaraan bermotor.

3. Pajak Bahan Bakar Kendaraan Bermotor (PBBKB). Pajak Bahan Bakar Kendaraan Bermotor adalah pajak atas bahan bakar kendaraan bermotor seperti : mobil, motor, alatalat bergerak dll yang dikenakan pada perorangan atau badan yang memiliki kendaraan bermotor yang digunakan dalam jalan darat serta kendaraan bermotor yang di operasikan di air karena hal tersebut termasuk dalam pajak bahan bakar kendaraan bermotor. 
4. Pajak Air Permukaan (PAP). Pajak Air Permukaan adalah pajak yang termasuk dalam pengambilan atau pemanfaatan Air Permukaan subjek dalam Pajak Air Permukaan adalah orang pribadi atau badan yang dapat melakuakan pengambilan atau yang pemanfaatan Air Permukaan, yang pengambilan atau pemanfaatan Air Permukaan untuk keperluan masyarakat di daerah sesuai dengan peraturan perundang-undangan dan pengambilan atau pemanfaatan Air Permukaan lainnya yang telah ditetapkan dalam Peraturan Daerah.

5. Pajak Rokok. Pajak Rokok adalah pajak yang dasar pengenaannya adalah cukai rokok, dan tarif pajak rokok ditetapkan sesuai dengan undang-undang yang ada sekarang yang dipungut oleh pemerintah pajak rokok tersebut digunakan untuk mendanai khususnya di pelayanan kesehatan yang ada didaerah khususnya buat masyarakat juga digunakan untuk suatu hubungan-hubungan hukum kepada yang berhak untuk mendapatkannya.

Pajak Kabupaten terdiri atas :

1. Pajak Hotel

2. Pajak Restoran

3. Pajak Hiburan

4. Pajak Reklame

5. Pajak Penerangan Jalan

6. Pajak Pengambilan Bahan Galian Golongan C dan

7. Pajak Parkir

Sistem Pemungutannya. Menurut Damas Dwi Anggoro (2017) Sistem Pemungutan Pajak Daerah terbagi atas 6 yaitu :

1. Pemungutan menggunakan Sistem Surat Ketetapan (SKP),

2. Pemungutan menggunakan Sistem Setor Tunai,

3. Pemungutan menggunakan Sistem Pembayaran di Muka,

4. Pemungutan menggunakan Sistem Pengkaitan,

5. Pemungutan menggunakan Sistem Benda Berharga dan,

6. Pemungutan menggunakan Sistem Kartu.

\section{METODE DAN TEKNIK PENERAPAN IPTEKS}

\subsection{Metode Penerapan Ipteks}

Data-data yang diperlukan dalam metode penerapan ipteks ini adalah : Gambaran Umum Dinas Pendapatan Daerah Provinsi Sulawesi Utara dan target dan realisasi pendapatan pajak daerah di Dinas Pendapatan Daerah Provinsi Sulawesi Utara. Data target dan realisasi pendapatan pajak daerah di Dinas Pendapatan Daerah Provinsi Sulawesi Utara Tahun 20172018 adalah sebagai berikut :

1. Pendapatan pajak kendaraan bermotor tahun 2017-2018.

2. Pendapatan bea balik nama kendaraan bermotor tahun 2017-2018.

3. Pendapatan pajak bahan bakar kendaraan bermotor tahun 2017-2018.

4. Pendapatan pajak air permukaan tahun 2017-2018.

5. Pendapatan pajak rokok tahun 2017-2018.

Penerapan atas ipteks perlu dilakukan pada Dinas Pendapatan Daerah Provinsi Sulawesi Utara guna melihat sejauh mana target dan realisasi pendapatan pajak daerah di Dinas Pendapatan Daerah Provinsi Sulawesi Utara pada tahun 2017-2018 yang berhubungan dengan ke lima pajak yang telah di uraikan satu per satu di data-data yang di perlukan dalam metode ini. Jenis data yang dilakukan di penelitian ini adalah data kuantitaf dan kualitatif.

\subsection{Teknik Penerapan Ipteks}

Teknik Penerapan ipteks dalam pengumpulan data adalah dengan mengumpulkan data yang bersifat sekunder dalam bentuk dokumen-dokumen yang ada seperti data target penerimaan pajak daerah tahun 2017 dan tahun 2018 dan data realisasi pendapatan pajak daerah tahun 2017 dan 2018 pada Dinas Pendapatan Daerah Provinsi Sulawesi Utara 
selanjutnya membandingkan data target pendapatan pajak daerah yang telah terealisasikan pada tahun 2017 dan data target pendapatan pajak yang telah terealisasikan pada tahun 2018, sesuai dengan sumber data sekunder target pendapatan pajak daerah pada tahun 2017-2018 dan realisasi pendapatan pajak daerah tahun 2017-2018 yang digunakan dalam penerapan ipteks ini.

\section{PEMBAHASAN}

\subsection{Gambaran Objek Penerapan Ipteks}

Pada tahun 1962 adalah tahun dimana Dinas Pendapatan Daerah Provinsi Sulawesi Utara dibentuk, kantor pajak daerah ini pada tahun 1984 mengelolah jenis pajak daerah yaitu pajak kendaraan bermotor (PKB), bea balik nama kendaraan bermotor (BBNKB), pajak bahan bakar kendaraan bermotor (PBBKB), dan retribusi daerah dan pada tahun 2000 ada perubahan pengelolaan jenis pajak daerah yaitu pajak pengambilan dan pemanfaatan air bawah tanah dan air permukaan, bea balik nama kendaraan di atas air, pajak kendaraan di atas air, pajak kendaraan bermotor, retribusi penggantian biaya cetak peta dan pelayanan jasa ketatausahaan. Pada tahun 2009 telah ditetapkan kembali perubahan jenis pajak daerah yang akan dikelola oleh Dinas Pendapatan Daerah yaitu menjadi 5 jenis yaitu Pajak Kendaraan Bermotor, Pajak Air Permukaan, dan Pajak Rokok, diberlakukan Pajak Rokok pada tahun 2014 dan pada tanggal 3 Januari 2016 sampai saat ini yang dipercayakan sebagai Kepala Badan Kepada Olvie Atteng, SE, M.Si dan juga Pembina Utama Madya. Dispenda Prov.Sulut di tahun 2011 memiliki 15 UPTD dan 4 Kantor Samsat Pembantu. Adapun 15 UPTD tersebut adalah :

1. UPTD Kabupaten Kepulauan Sangihe

2. UPTD Kabupaten Minahasa

3. UPTD Kabupaten Minahasa Selatan

4. UPTD Kabupaten Minahasa Tenggara

5. UPTD Kabupaten Minahasa Utara

6. UPTD Kota Manado

7. UPTD Kota Bitung

8. UPTD Kota Tomohon

9. UPTD Kabupaten Bolaang Mongondow

10. UPTD Kabupaten Bolaang Mongondow Selatan

11. UPTD Kabupaten Bolaang Mongondow Timur

12. UPTD Kabupaten Bolaang Mongondow Utara

13. UPTD Kota Kotamobagu

14. UPTD Kabupaten Kepulauan Siau, Tagulandang, Biaro

15. UPTD Kabupaten Kepulauan Talaud

Adapun 4 Kantor Samsat Pembantu adalah :

1. Samsat Pembantu Amurang

2. Samsat Pembantu Airmadidi

3. Samsat Pembantu Tomohon

4. Samsat Pembantu Talaud

\subsection{Pembahasan}

Berdasarkan penerapan ipteks yang telah dilakukan, diketahui bahwa target dan realisasi pendapatan pajak daerah di Provinsi Sulawesi Utara pada tahun 2017-2018, sesuai dengan pendapatan pajak daerah yang berhubungan dengan ke lima pajak yaitu : PKB, BBNKB, PBBKB, PAP, dan PR. Dari ke lima pajak ini yang akan di teliti dalam target dan realisasi pendapatan pajak daerah di Dispenda Prov.Sulut sesuai dengan hasil data penelitian yang diambil sesuai dengan data sekuder dikantor. Berikut merupakan tabel data pendapatan pajak daerah pada Dispenda Provinsi Sulawesi Utara. 
Tabel 1. Target Pendapatan Pajak Pajak Daerah Dinas Pendapatan Daerah Provinsi Sulawesi Utara Tahun 2017

\begin{tabular}{|c|c|c|c|}
\hline Uraian & $\begin{array}{c}\text { Target } \\
\text { TA. } 2017 \\
\end{array}$ & $\begin{array}{c}\text { s/d } 30 \text { November } \\
2017 \\
\end{array}$ & $\%$ \\
\hline PENDAPATAN DAERAH & 3.723.697.617.672 & 3.392.068.712.658 & 91,09 \\
\hline Pendapatan Asli Daerah (PAD) & 1.094.319.346.536 & 1.037.817.680.867 & 94,84 \\
\hline Pajak Daerah & 939.710 .896 .000 & 889.421 .881 .229 & 94,65 \\
\hline Retribusi Daerah & 78.917 .735 .880 & 66.352 .635 .219 & 84,08 \\
\hline Hasil Pengelolaan Kekayaan Daerah yang dipisahkan & 31.234.932.522 & 31.361.351.498 & 100,40 \\
\hline Lain Lain Pendapatan Asli Daerah yang Sah & 44.455 .782 .134 & 50.681 .812 .921 & 114,00 \\
\hline Dana Perimbangan & 2.552.893.038.136 & 2.277.765.798.791 & 89,22 \\
\hline Bagi Hasil Pajak/Bagi Hasil Bukan Pajak & 109.500.060.136 & 94.455 .767 .141 & 86,26 \\
\hline Dana Alokasi Umum (DAU) & 1.390.272.639.000 & 1.390 .272 .639 .000 & 100,00 \\
\hline Dana Alokasi Khusus (DAK) & 1.053 .120 .339 .000 & 793.037.392.650 & 75,30 \\
\hline Lain Lain Pendapatan Daerah yang Sah & 76.485.233.000 & 76.485.233.000 & 100,00 \\
\hline Pendapatan Hibah & 10.645 .500 .000 & 10.645 .500 .000 & 100,00 \\
\hline Dana Penyesuaian \& Otonomi Khusus & 50.839 .733 .000 & 50.839 .733 .000 & 100,00 \\
\hline $\begin{array}{l}\text { Bantuan Keuangan dari Provinsi atau Pemerintah } \\
\text { Daerah Lainnya }\end{array}$ & 15.000 .000 .000 & 15.000 .000 .000 & 100,00 \\
\hline
\end{tabular}

Dari data diatas dapat diketahui hasil dari perhitungan target dan realisasi dari pajak daerah tersebut, bahwa realisasi PAD Prov.Sulut sampai pada bulan November Tahun 2017 Rp.1.037.817.680.867 atau 94,84\% tidak mencapai target penerimaan pajak dari Target TA. Tahun 2017 sebesar Rp.1.094.319.346.536 dan realisasi Lain Lain PAD yang Sah Provinsi Sulawesi Utara sampai pada bulan November Tahun 2017 Rp. 76.485.233.000 atau 100,00\% mencapai target penerimaan pajak dari Target TA. Tahun 2017 sebesar Rp. 76.485.233.000 atau $100,00 \%$.

Tabel 2. Target Pendapatan Pajak Pajak Daerah Dinas Pendapatan Daerah Provinsi Sulawesi Utara Tahun 2018

\begin{tabular}{|c|c|c|c|c|}
\hline NO & URAIAN & TARGET TA. 2018 & $\begin{array}{l}\text { REALISASI S/D } \\
\text { 8 JANUARI } 2017 \\
\end{array}$ & $\%$ \\
\hline \multirow[t]{6}{*}{$\mathbf{1}$} & PAJAK DAERAH & Rp. 1.000.049.416.000 & Rp. 10.375.373.898 & 1,04 \\
\hline & - Pajak Kendaraan Bermotor (PKB) & RP. 318.136 .824 .684 & Rp. $\quad 6.643 .365 .398$ & 2,09 \\
\hline & $\begin{array}{l}\text { - Bea Balik Nama Kendaraan Bermotor } \\
\text { (BBN-KB) }\end{array}$ & Rp. $\quad 301.685 .786 .800$ & Rp. $\quad 3.732 .008 .500$ & 1,24 \\
\hline & - Pajak Air Permukaan (PAP) & 1.625 .520 .800 & Rp. & - \\
\hline & $\begin{array}{l}\text { - Pajak Bahan Bakar Kendaraan Bermotor } \\
\text { (PBB-KB) }\end{array}$ & Rp. $\quad 220.713 .783 .716$ & Rp. & \\
\hline & - Pajak Rokok (PR) & Rp. $\quad 157.887 .500 .000$ & Rp. & - \\
\hline \multirow[t]{5}{*}{2} & LAIN LAIN PAD YANG SAH & 6.050.000.000 & 136.516.970 & 2,26 \\
\hline & - Denda Pajak Kendaraan Bermotor & 5.175 .000 .000 & 136.516 .970 & 2,64 \\
\hline & - Denda BEA Balik Nama Kendaraan Bermotor & $\mathrm{Rp}$. & Rp. & - \\
\hline & - Pendapatan Kerjasama Pemanfaatan Kekayaan Daerah & 875.000 .000 & Rp. & - \\
\hline & - Pendapatan Dari Pengembalian & Rp. & Rp. & - \\
\hline
\end{tabular}

Dari data diatas dapat diketahui hasil dari perhitungan target dan realisasi dari pajak daerah tersebut, bahwa realisasi PAD Prov.Sulut Bulan Januari Tahun 2018 Rp. 1.000.049.416.000 target penerimaan pajak dari Target TA. Tahun 2017 sebesar Rp.1.094.319.346.536 atau 94,84\% dan realisasi Lain Lain PAD yang Sah Provinsi Sulawesi Utara sampai pada bulan Januari Tahun 2017 Rp. 136.516 .970 atau 2,26\% target penerimaan pajak dari Target TA. Tahun 2017 sebesar Rp. 76.485.233.000. 


\section{KESIMPULAN DAN SARAN}

\subsection{Kesimpulan}

Dari hasil penerapan ipteks di Dinas Pendapatan Daerah (Dispenda) Provinsi Sulawesi Utara dapat di simpulkan bahwa diketahui hasil perhitungan target dan realisasi pendapatan pajak daerah di Provinsi Sulawesi Utara pada tahun 2017-2018 pada Dispenda Prov.Sulut mengalami penurunan di tahun 2017-2018 dan Realisasi Lain Lain PAD yang Sah Provinsi Sulawesi Utara Tahun 2017 mencapai target 100\% penerimaan pajak dari Target TA. Tahun 2017.

\subsection{Saran}

Saran dari penerapan ipteks ini adalah agar perlu ditingkatkan aktivitas kepada setiap Wajib Pajak dalam bentuk mensosialisasikan mengenai sangat penting Wajib Pajak membayar pajak dengan tepat waktu, karena itu merupakan kewajiban dari setiap Wajib Pajak dan tidak terjadi denda terhadap Wajib Pajak sehingga Dispenda Prov.Sulut dapat mencapai target pendapatan pajak daerah dan dapat terealisasikan setiap tahun.

\section{DAFTAR PUSTAKA}

Andrea Meylita Widyasti Parera, Teguh Erawati. 2014. Pengaruh Kesadaran Wajib Pajak, Sanksi Perpajakan, Pengetahuan Perpajakan, Dan Pelayanan Fiskus. Jurnal Akuntansi Jurnal Akuntansi Vol. 5 No. 1 Juni 2014.

Anggoro, D. D. 2017. Pajak Daerah dan Retribusi Daerah. Malang. UB Press.

BAPPEDA - BPS kota Manado. 2013. Sulut Dalam Angka 2013, Manado.

Ginting, Ari Mulianta. 2012. Pengaruh Dana Alokasi Umum dan Pendapatan Asli Daerah

Terhadap Belanja Pemerintah Daerah Di Provinsi Di Pulau Jawa. Kajian Vol 17 No.3

September 2012.

Halim, Abdul. 2007. Manajemen Keuangan Daerah : Seri Bunga Rampai. Yogyakarta:BPFE

Kuncoro, Mudjarat. 2003. Metode Riset untuk Bisnis \& Ekonomi. Erlangga. Jakarta

Mardiasmo. 2011. Perpajakan, Edisi Revisi. Yogyakarta: Andi.

Phaureula Artha Wulandari, Emy Iryanie. 2018. Pajak Daerah dalam Pendapatan Asli Daerah. Yogyakarta. Deepublish.

Rakhmad Rinaldi Wahfar, Abubakar Hamzah I, Mohd. Nur Syechalad II., 2014 " Analisis Pajak Kendaraan Bermotor (Pkb) Dan Bea Balik Nama Kendaraan Bermotor (Bbnkb) Sebagai Salah Satu Sumber Penerimaan Pendapatan Asli Daerah (Pad) Kabupaten Pidie "Volume 2, No. 1,Februari (2014)

Sarijan. 2009 . Strategi DispendaDalam Meningkatkan Pendapatan Asli Daerah dari Sektor

PKB dan BBKNKB di Propinsi Sumatera Selatan, Tesis. Universitas Gadjah Mada, Yogyakarta.

Sugianto. 2017. Pajak dan Retribusi Daerah (Pengelolaan Pemerintah Daerah dalam Aspek Keuangan, Pajak, dan Retribusi Daerah). Jakarta. Grasindo.

Sutrisno. 1984. Konsep Pendapatan Asli Daerah. Rajawali. Jakarta. 